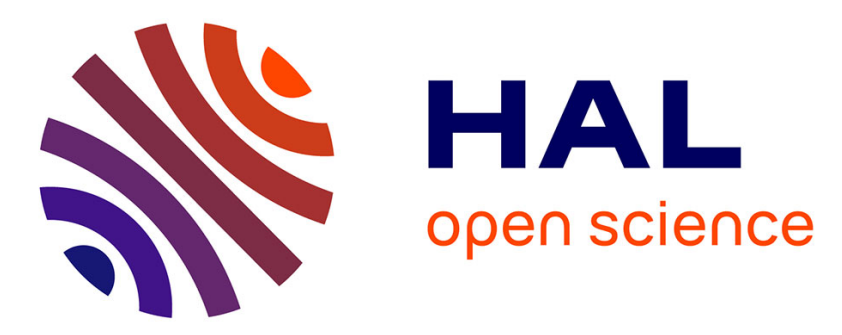

\title{
Modeling variable-density flow in saturated-unsaturated porous media: An advanced numerical model
}

Anis Younes, Behshad Koohbor, Benjamin Belfort, Philippe Ackerer, Joanna

Doummar, Marwan Fahs

\section{- To cite this version:}

Anis Younes, Behshad Koohbor, Benjamin Belfort, Philippe Ackerer, Joanna Doummar, et al.. Modeling variable-density flow in saturated-unsaturated porous media: An advanced numerical model. Advances in Water Resources, 2022, 159, pp.104077. 10.1016/j.advwatres.2021.104077 . hal-03526449

\section{HAL Id: hal-03526449 \\ https://hal.science/hal-03526449}

Submitted on 14 Jan 2022

HAL is a multi-disciplinary open access archive for the deposit and dissemination of scientific research documents, whether they are published or not. The documents may come from teaching and research institutions in France or abroad, or from public or private research centers.
L'archive ouverte pluridisciplinaire HAL, est destinée au dépôt et à la diffusion de documents scientifiques de niveau recherche, publiés ou non, émanant des établissements d'enseignement et de recherche français ou étrangers, des laboratoires publics ou privés. 
2

3

4

5

6

7

8

9

10

11

12

13

14

15

16

17

18

19

20

21

22

23

24

25

26

27

28

29

39

40

41

42

43

44

45

\title{
Modeling variable-density flow in saturated-unsaturated porous media: An advanced numerical model
}

\author{
Anis Younes, ${ }^{1}$ Behshad Koohbor, ${ }^{2}$ Benjamin Belfort, ${ }^{1}$ Philippe Ackerer, ${ }^{1}$ Joanna Doummar, ${ }^{3}$ \\ Marwan Fahs ${ }^{1 *}$ \\ ${ }^{1}$ Institut Terre et Environnement de Strasbourg, Université de Strasbourg, CNRS, ENGEES, UMR 7063 \\ ${ }^{2}$ BRGM (French Geological Survey), Orléans, France \\ ${ }^{3}$ Department of Geology, American University of Beirut, Beirut, Lebanon
}

Submitted to Advances in Water Resources

30 Contact author: Marwan Fahs

31 E-mail: fahs@unistra.fr 
Abstract

36 Modeling variable-density flow in unconfined aquifers is a challenging task because of the nonlinear coupling between variably saturated flow and contaminant transport. This results in a highly nonlinear system since the strongly nonlinear Richards flow equation is, in addition, coupled to the advection-dispersion transport equation by viscosity and density variation. The solution of such a nonlinear system is often subject to convergence issues and can be very expansive in terms of computational time, especially for large-scale problems. Conventional numerical algorithms based on the sequential approach and the classical finite difference or finite element methods with the first-order backward Euler time integration scheme are generally inefficient and/or do not provide satisfactory results. In this work, we develop a new efficient and accurate 2D numerical model for the transport of dense contaminants in unsaturated porous media that allows for the simulation of large-scale problems. This research describes a new model that combines advanced spatial discretization methods (mixed hybrid approximation method) with higher-order time integration techniques via the method of lines (MOL). The latter allows one to adapt the time step's size and the order of the time integration to improve the computational efficiency while maintaining accuracy. The robustness and accuracy of the new model are shown by comparison against a widely used commercial code based on the standard finite element method. The applicability of the developed model to a large-scale problem is then investigated by simulating saltwater intrusion under a climate change projection and long-term pumping regimes for the Akkar coastal aquifer in Lebanon using a simplified 2D conceptual model.

Key words: unsaturated flow, variable-density flow, mixed finite element method, discontinuous finite element method, multi-Point flux approximation, method of lines, field simulation. 


\section{Introduction}

Many saturated-unsaturated aquifer systems are subject to the pollution of soils and groundwater resources by dense contaminants such as leachates derived from waste disposal sites, agricultural activity, or sanitary landfills. Contamination by saltwater is a major environmental issue that occurs, for instance, with the leakage of brine beneath the salt lakes, flooding of coastal areas by seawater, saltwater intrusion in coastal aquifers due to overpumping, tidal effects or sea-level rise. For such situations, fluid flow and solute transport equations are coupled by the fluid density.

Several studies have focused on variable-density flow in saturated porous media [1-4] since the effect of density variations on the flow behavior in the saturated zone is much more significant than in the unsaturated zone. Indeed, in the unsaturated zone, the density variation in the liquid phase is much less important than the density variation between the liquid and the air phase (about three orders of magnitude). Simmons et al. [5] investigated the migration of a dense contaminant plume through the unsaturated zone using laboratory experiments. They showed that the unsaturated zone and position of the water table must be considered in contamination studies in order to predict the migration pathways, rates and the ultimate fate of dense contaminant plumes [5]. Oostrom et al. [6] and Dane et al. [7] investigated saturated variable-density flow with a narrow unsaturated zone in their physical models. They showed that the development of plume instabilities depends on the density difference between the plume and groundwater, the horizontal Darcy velocity, the contaminant leakage rates, the source dimensions, the hydrodynamic dispersion and the permeability of the porous media. Ouyang and Zheng [8] numerically showed that density-driven transport is significant for dissolved chemicals through unsaturated sandy soils. Using numerical simulations, Boufadel et al. [9] showed that concentration-dependent viscosity effects below dry salt lakes are 
84 significant under fully saturated conditions, but have minor effects under unsaturated flow 85 conditions.

86 Considering both saturated and unsaturated zones for coupled flow and transport processes 87 can improve the representativeness of simulations when investigating evaporation and salt 88 accumulation effects on riparian freshwater lenses [10] or when investigating the effect of 89 water table salinization [11-14] or the effect of the slope of the seaward boundary on saltwater 90 intrusion [15-17].

91 Including the unsaturated zone when modeling variable-density flow problems requires the 92 solution of a coupled flow-transport nonlinear system. In such a system, the flow is ruled by 93 the Richards' equation (RE), which uses nonlinear constitutive relationships between 94 hydraulic conductivity, water content, and pressure head [18, 19]. Because of these 95 nonlinearities, providing an accurate solution of RE is challenging due to convergence issues 96 and high time consumption, particularly in the presence of sharp wetting fronts, as when 97 simulating infiltration into initially dry soils [20]. These difficulties are increased in the case 98 of a dense contaminant because of additional nonlinearities induced by density variations 99 which require coupling between the RE and the advection-dispersion transport equation.

100 Because of nonlinearities and the absence of analytical solutions, numerical models are 101 valuable tools for solving these complex problems and for understanding and predicting the 102 propagation of contaminations in the aquifers. However, most of the existing numerical 103 models do not provide satisfactory results when applied to unsaturated variable-density flow 104 problems, essentially because:

105 - Classical spatial discretization methods such as finite element (FE) or finite difference 106 (FD) methods may not provide an accurate velocity field, especially in the case of 107 highly heterogeneous and/or anisotropic domains [21, 22]. 
- When applied to the transport equation, the classical methods provide results with significant unphysical oscillations for advection-dominated transport. If combined with first-order upstream techniques, they suffer from excessive numerical dispersion [23].

- Temporal discretization is often based on the first-order backward Euler scheme, which does not allow large time steps and, as a consequence, induces excessive computational time.

- Coupling between flow and transport equations is usually performed via a sequential approach with an empirical time-stepping technique without any control over the temporal truncation error, which may lead to inaccurate results [24].

To overcome these difficulties, in this work, we combine advanced spatial and temporal approximation methods. The flow equation is solved using the mixed hybrid finite element (MHFE) method [25]. This method simultaneously approximates both pressure and fluxes with the same order of convergence. The MHFE method is (i) locally conservative, (ii) well adapted for general unstructured meshes, and (iii) can easily handle full permeability tensors. The unknowns with the hybrid formulation are the traces of the pressure at edges/faces [26]. The lumped form of the MHFE method proposed in [27] is employed in this work to avoid spurious oscillations encountered with transient simulations in the case of sharp wetting fronts $[28]$.

For the transport equation, the discontinuous Galerkin (DG) method is used to discretize the advection equation and combined with the multi-point flux approximation (MPFA) method for the discretization of the dispersion equation [29]. The DG method is strictly conservative at the element level. It yields accurate results for problems involving sharp fronts [30]. DG is used with an implicit time discretization that avoids $(i)$ time-step limitation caused by the 
132 Courant-Friedrichs-Lewy (CFL) condition of explicit schemes and (ii) the use of a slope2133 limiting procedure to ensure the stability of the results [29]. A discontinuous linear 134 approximation is used for the concentration at each element of the mesh. Often, the DG 135 degrees of freedom (DOFs) correspond to the discontinuous concentration at the nodes inside 136 each element (see, for instance, $[31,32])$. The DOFs used here are the mean concentration and 137 the horizontal and vertical components of the concentration gradient at each element [29]. 138 This choice allows one to imitate the upwind finite volume (FV) method when only the first 139 equation corresponding to the mean concentration value is kept. Further, this choice of DOFs allows one to combine the DG method with MPFA for the approximation of dispersion without any operator splitting [29]. The classical methods, like FD or FV, based on two-point flux approximation (TPFA) to compute the flux between two adjacent elements, may not converge unless the grid is K-orthogonal [33]. The MPFA method calculates the flux at an element boundary using multiple surrounding elements; therefore, it is well adapted for general grids and full dispersion tensors [34].

The spatial discretization (MHFE_DG_MPFA) based upon the combination of MHFE, DG, and MPFA methods was shown to be robust and accurate for modeling variable-density flow in saturated porous media [35] and is extended in this work for unsaturated flow.

Higher-order time integration methods are used via the method of lines (MOL) to allow large time steps and improve the efficiency of the model. The flow and transport equations are solved simultaneously in a single step, which avoids slow convergence encountered with the sequential approach. The MOL allows one to adapt the time step's length and the order of the temporal discretization (up to 5 using the Backward Difference Formulas) in order to reduce the computational time while maintaining accuracy. The MOL is effective for the solution of the RE in the unsaturated zone [36] as well as for variable-density flow in saturated porous media [37]. In this work, the MOL is used for the first time for dense contaminant transport in 
157 unsaturated porous media. Variable-order and variable-step size time integration are 158 performed using the DASPK [38] time solver.

\section{2. Governing Equations}

160 Dense contaminant transport in unsaturated porous media is governed by the Darcy161 Buckingham's law, the mass conservation of the fluid and the advection-dispersion transport 162 equation. Assuming the Boussinesq approximation is valid, the flow in the unsaturated zone 163 can be written in terms of equivalent freshwater head, as follows:

$$
\frac{\partial \theta}{\partial t}=\left(c(h)+S_{S} \frac{\theta(h)}{\theta_{S}}\right) \frac{\partial H}{\partial t}=-\nabla \cdot \boldsymbol{q}+q_{S}
$$

$$
\boldsymbol{q}=-k_{r} \boldsymbol{K}\left(\nabla H+\frac{\rho-\rho_{0}}{\rho_{0}} \nabla z\right)
$$

166 where $c(h)=\partial \theta / \partial h$ is the specific moisture capacity $\left[\mathrm{L}^{-1}\right], S_{S}$ the specific mass storativity 167 related to head changes $\left[\mathrm{L}^{-1}\right], \theta$ the current water content $\left[\mathrm{L}^{3} \mathrm{~L}^{-3}\right], \theta_{S}$ the saturated water 168 content $\left[\mathrm{L}^{3} \mathrm{~L}^{-3}\right], H=h+z$ the equivalent freshwater head $[\mathrm{L}], h=\frac{P}{\rho_{0} g}$ the pressure head, $P$ 169 the pressure $[\mathrm{Pa}], z$ the upward vertical coordinate $[\mathrm{L}], t$ the time $[\mathrm{T}], \boldsymbol{q}$ the Darcy's velocity $170\left[\mathrm{LT}^{-1}\right], q_{S}$ the sink term $\left[\mathrm{T}^{-1}\right], k_{r}$ the relative conductivity $[-], \boldsymbol{K}=\frac{\rho_{0} g}{\mu} \boldsymbol{k}$ the hydraulic 171 conductivity tensor $\left[\mathrm{LT}^{-1}\right], \rho_{0}$ the density of the displaced fluid $\left[\mathrm{ML}^{-3}\right], g$ the gravity 172 acceleration $\left[\mathrm{LT}^{-2}\right], \mu$ the fluid dynamic viscosity $\left[\mathrm{ML}^{-1} \mathrm{~T}^{-1}\right], \boldsymbol{k}$ the permeability tensor 173 dependent only on the porous medium $\left[\mathrm{L}^{2}\right]$, and $\rho$ the fluid density $\left[\mathrm{ML}^{-3}\right]$.

174 The solute transport in the unsaturated zone is ruled by the advection-dispersion equation: 


$$
\frac{\partial(\theta C)}{\partial t}+\nabla \cdot(\boldsymbol{q} C)-\nabla \cdot(\boldsymbol{D} \nabla C)=q_{S} C
$$

where $C[-]$ is the scaled concentration and $\boldsymbol{D}$ the dispersion tensor given by:

$$
\boldsymbol{D}=D_{m} \boldsymbol{I}+\left(\alpha_{L}-\alpha_{T}\right) \boldsymbol{q} \otimes \boldsymbol{q} /|\boldsymbol{q}|+\alpha_{T}|\boldsymbol{q}| \boldsymbol{I}
$$

178 with $\alpha_{L}$ and $\alpha_{T}$ the longitudinal and transverse dispersivities [L], $D_{m}$ the pore water 179 diffusion coefficient $\left[\mathrm{L}^{2} \mathrm{~T}^{-1}\right]$, and $\boldsymbol{I}$ the unit tensor.

180 We use the standard van Genuchten [39] model to define the relation between water content 181 and pressure head:

$$
S_{e}=\frac{\theta(h)-\theta_{r}}{\theta_{s}-\theta_{r}}= \begin{cases}\frac{1}{\left(1+(\alpha|h|)^{n}\right)^{m}} & h<0 \\ 1 & h \geq 0\end{cases}
$$

183 where $\alpha\left[L^{-1}\right]$ and $n[-]$ are the van Genuchten parameters, $m=1-1 / n, S_{e}[-]$ the effective 184 saturation, and $\theta_{r}$ the residual water content $\left[\mathrm{L}^{3} \mathrm{~L}^{-3}\right]$.

185 The conductivity-saturation relationship is analytically derived from the Mualem [40] model, 186 as proposed by van Genuchten [39]:

$$
k_{r}=S_{e}^{1 / 2}\left[1-\left(1-S_{e}^{1 / m}\right)^{m}\right]^{2}
$$

188 Darcy velocity $\boldsymbol{q}$ in equation (2) depends on both the pressure head $h$ and the concentration $189 C$

190 The flow and transport equations are coupled by the state equations. In the case of salt 191 contamination, we can use the polynomial approximations given in [1]: 
where $\rho_{0}$ and $\rho_{1}$ are densities of freshwater and saltwater and $\mu_{0}$ the freshwater viscosity. Different state equations may be used for density or viscosity [1].

\section{The numerical model}

The system of nonlinear equations (1)-(7), valid in 3D domains, is solved hereafter for $2 \mathrm{D}$ vertical domains using adapted advanced numerical methods that allow an accurate estimation of the velocity and concentration distributions for heterogeneous domains and unstructured meshes. The main stages to form the final system to be solved are summarized hereafter for a general triangular mesh.

\subsection{The lumped MHFE method for modeling fluid flow}

202 With the classical standard FE method, the head is approximated linearly inside each element 203 using standard chapeau functions, and hence, the velocity is constant at the element level. 204 With the MHFE method, we assume a linear approximation for the velocity $\boldsymbol{q}$ inside each 205 triangle $E$ using the linear Raviart-Thomas basis functions:

$$
\boldsymbol{q}=\sum_{j=1}^{3} Q_{j}^{E} \boldsymbol{w}_{j}^{E}
$$

207 where $Q_{j}^{E}$ is the flux across the edge $j$ of $E$ and $\boldsymbol{w}_{j}^{E}$ is the Raviart-Thomas basis function 208 [41].

209 The mass lumping procedure is used to avoid over- and undershoots observed for transient 210 simulations with small time steps $[27,28]$. The basic idea of this procedure is to consider 
211 steady-state flow (the mean head at the element $E$ is $H_{E}=\left(T H_{1}^{E}+T H_{2}^{E}+T H_{3}^{E}\right) / 3$ ), and then

212 the transient component is directly added to the expression of the flux [35]:

$$
Q_{i}^{E}=\sum_{j} N_{i j}^{E}\left(T H_{j}^{E}+\frac{\rho_{E}-\rho_{0}}{\rho_{0}} z_{j}^{E}\right)-\frac{|E|}{3} r_{E} \frac{d T H_{i}^{E}}{d t}+\frac{Q_{S}^{E}}{3}
$$

214 where $T H_{i}^{E}$ (resp. $z_{i}^{E}$ ) is the mean head (resp. mean elevation) of the edge $i$ of $E$ with $215 T H_{i}=T h_{i}+z_{i}, T h_{i}$ is the mean pressure head, $j$ is an edge of $E, N$ is a local matrix of 216 coefficients $N_{i j}^{E}=-k_{r}^{E} \frac{\operatorname{det}\left(\boldsymbol{K}_{E}\right)}{|E|} \boldsymbol{r}_{i}^{T} \cdot \boldsymbol{K}_{E}{ }^{-1} \cdot \boldsymbol{r}_{j}$ where $\boldsymbol{r}_{i}$ is the edge vector face to the vertex $i$ of 217 the element $E$ (see Younes et al. [42] for more details), $|E|$ is the area of $E$, $218 r_{E}=c\left(h_{E}\right)+S_{S} \theta\left(h_{E}\right) / \theta_{S}$ is the accumulation term in Richards' equation, $h_{E}$ is the mean 219 pressure head at $E$, and $Q_{S}^{E}=\int_{E} q_{S}$ is the sink term on $E$.

220 The final flow system is formed by imposing continuity of heads $\left(T H_{i}^{E}=T H_{i}^{E^{\prime}}\right)$ and fluxes $221\left(Q_{i}^{E}+Q_{i}^{E^{\prime}}=0\right)$ between the adjacent elements $E$ and $E^{\prime}$ having a common edge $i$ :

$$
\sum_{j} N_{i j}^{E}\left(T H_{j}^{E}+\frac{\rho_{E}-\rho_{0}}{\rho_{0}} z_{j}^{E}\right)+\sum_{j} N_{i j}^{E^{\prime}}\left(T H_{j}^{E^{\prime}}+\frac{\rho_{E^{\prime}}-\rho_{0}}{\rho_{0}} z_{j}^{E^{\prime}}\right)-\left(\frac{|E|}{3} r_{E}+\frac{\left|E^{\prime}\right|}{3} r_{E^{\prime}}\right) \frac{d T H_{i}^{E}}{d t}+\frac{Q_{S}^{E}}{3}+\frac{Q_{S}^{E^{\prime}}}{3}=0
$$

224 The indices $i$ and $j$ are global, and the system is solved for the mean heads at edges $T H_{i}$.

225 In the case of a Dirichlet condition with a prescribed head $H_{i m p}$ at the boundary edge $i$, 226 equation (10) is replaced by $T H_{i}=H_{i m p}$. If the boundary edge $i$ has a prescribed flux $Q_{i m p}$ 227 (Neumann boundary condition), equation (10) is replaced by $Q_{i}^{E}+Q_{i m p}=0$. 
228 Note that the system of equations (10) is highly nonlinear since (i) the local matrix $N$ and the 1

$$
\theta \frac{\partial C}{\partial t}+\boldsymbol{q} \nabla C+\nabla \cdot \boldsymbol{q}_{D}=0 .
$$

235 With $\boldsymbol{q}_{D}=-\boldsymbol{D} \nabla C$, the dispersive flux, assumed to have a constant divergence over the 236 element $E$ :

$$
\nabla \cdot \boldsymbol{q}_{D}=\frac{1}{|E|} \sum_{i} Q d_{i}^{E}
$$

238 where $Q d_{i}^{E}$ is the dispersive flux across the edge $i$ of $E$.

239 The concentration inside the element $E$ is approximated with linear discontinuous functions:

$$
C^{E}=\sum_{i=1}^{3} C_{E, i} \phi_{E, i}
$$

241 with $\phi_{E, i}$ being the interpolation function and $i$ a local index that refers to the $i^{\text {th }}$ DOF $C_{E, i}$ of 242 the concentration inside the element $E$.

243 In the literature, the DOFs are often chosen (see, for instance, [43]) to be the concentration at 244 the nodes and $\phi_{E, i}$, the classical chapeau functions. In this work, the DOFs are the mean 
concentration $C_{E, 1}$ and the components of the concentration gradient $C_{E, 2}$ and $C_{E, 3}$, with the corresponding interpolation functions:

$$
\phi_{E, 1}=1, \quad \phi_{E, 2}=\left(x-x_{E}\right), \quad \quad \phi_{E, 3}=\left(z-z_{E}\right),
$$

where $x$ and $z$ are horizontal and vertical coordinates, and $x_{E}$ and $z_{E}$ are the coordinates of the center of the element $E$. Thus, the polynomial approximation of the concentration inside the element $E$ is $C^{E}=C_{E, 1}+C_{E, 2}\left(x-x_{E}\right)+C_{E, 3}\left(z-z_{E}\right)$.

The variational formulation of $\mathrm{Eq}(11)$ using the test function $\phi_{E, i}$ is:

$$
\int_{E} \theta \frac{\partial C}{\partial t} \phi_{E, i}-\int_{E} C \nabla \cdot\left(\boldsymbol{q} \phi_{E, i}\right)+\int_{E} \nabla \cdot\left(\boldsymbol{q} C \phi_{E, i}\right)+\int_{E} \phi_{E, i} \nabla \cdot \boldsymbol{q}_{D}=0
$$

253 Using Green's formula and Eq (12) and Eq (13), we obtain:

$$
\sum_{j} \frac{d C_{E, j}}{d t} \theta_{E} \int_{E} \phi_{E, j} \phi_{E, i}-\sum_{j} \int_{E} C_{E, j} \phi_{E, j} \nabla \cdot\left(\boldsymbol{q} \phi_{E, i}\right)+\sum_{j} \int_{j} C_{j}^{*} \phi_{E, i} \boldsymbol{q} \cdot \boldsymbol{\eta}_{j}^{E}+\sum_{j} Q d_{j}^{E} \int_{E} \phi_{E, i}=0
$$

255 where $C_{j}^{*}$ is the upstream concentration at the edge $j, \boldsymbol{\eta}_{j}^{E}$ is the unit outward normal vector 256 to the edge $j$ of $E$, and $\boldsymbol{q}$ is the velocity obtained by substituting equation (9) into equation $257(8)$

258 Equation (15) is written for the three test functions $\phi_{E, i}(i=1,2,3)$ for each element $E$. The 259 index $j(j=1,2,3)$ refers to the $j^{\text {th }}$ DOF of the concentration in the element $E$ in the two 260 first terms of $\mathrm{Eq}(15)$ and to the $j^{\text {th }}$ edge of $E$ for the last two terms in equation (15).

261 The upstream concentration $C_{j}^{*}$ at the edge $j$ can be written as follows: 


$$
C_{j}^{*}=\tau_{j}^{E} C_{j}^{E}+\left(1-\tau_{j}^{E}\right) C_{j}^{E^{\prime}}
$$

263 with $\tau_{j}^{E}=1$ for an outward flux $\left(\boldsymbol{q} \cdot \boldsymbol{\eta}_{j}^{E} \geq 0\right)$, else $\tau_{j}^{E}=0$.

264 Thus, $C_{j}^{*}$ corresponds to $C_{j}^{E}$, the concentration at the edge $j$ calculated using the polynomial 10

approximation of the concentration at the element $E$, or $C_{j}^{E^{\prime}}$, the concentration at $j$ calculated using the polynomial approximation of the concentration at the element $E$, sharing the edge $j$ with $E$.

268 Equation (15) yields three equations for each element $E$ having 3 adjacent elements $269(E 1, E 2, E 3):$

$$
[A]\left(\begin{array}{l}
\frac{d C_{E, 1}}{d t} \\
\frac{d C_{E, 2}}{d t} \\
\frac{d C_{E, 3}}{d t}
\end{array}\right)=[B]\left[\begin{array}{l}
C_{E, 1} \\
C_{E, 2} \\
C_{E, 3}
\end{array}\right]-\left[M^{0}\right]\left[\begin{array}{l}
C_{E, 1} \\
C_{E, 2} \\
C_{E, 3}
\end{array}\right]-\sum_{\ell=1}^{3}\left[M^{\ell}\right]\left[\begin{array}{l}
C_{E \ell, 1} \\
C_{E \ell, 2} \\
C_{E \ell, 3}
\end{array}\right]-\left[\begin{array}{c}
\sum_{j} Q d_{j}^{E} \\
0 \\
0
\end{array}\right]
$$

with:

$$
\begin{array}{ll}
A_{i, j}=\theta_{E} \int_{E} \phi_{E, j} \phi_{E, i} & B_{i, j}=\int_{E} \phi_{E, j} \nabla \cdot\left(\boldsymbol{q} \phi_{E, i}\right) \\
M_{i, j}^{0}=\sum_{\ell} \tau_{\ell}^{E} \boldsymbol{q} \cdot \boldsymbol{\eta}_{\ell}^{E} \int_{\ell} \phi_{E, i} \phi_{E, j} & M_{i, j}^{\ell}=\left(1-\tau_{\ell}^{E}\right) \boldsymbol{q} \cdot \boldsymbol{\eta}_{\ell}^{E} \int_{\ell} \phi_{E, i} \phi_{E \ell, j}
\end{array}
$$

273 To avoid operator splitting between advection and dispersion, the dispersive flux $Q d_{j}^{E}$ in 274 equation (17) is approximated using the MPFA method. The latter has similar properties to 275 the MFE method since both are locally conservative and can handle unstructured meshes and 276 anisotropic and heterogeneous domains. The two methods can be equivalent for some specific 277 situations $[34,44]$. However, contrary to the MHFE method, which uses the concentration at 
278 the edges as DOFs, MPFA uses the mean concentration at each element as DOFs. Hence, the

279 discrete approximation of $Q d_{j}^{E}$ can be directly added to the system of equations (17), which 280 avoids the necessary operator splitting if the MHFE method is used for dispersion, as in [30].

284 To calculate $Q d_{j}^{E}$ with the MPFA method, we assume that the concentration inside the sub285 cell $\left(O, F_{1}, G, F_{2}\right)$ formed by the node $O$, the center $G$, and the mid-edges $F_{1}$ and $F_{2}$ (gray 286 area in the Figure 1) is linear. Hence, it can be approximated using $C_{E, 1}, \lambda_{1}$ and $\lambda_{2}$ the 287 concentrations at respectively $G$ and the two continuity points $f_{1}$ and $f_{2}$ located at $288 \quad \frac{O f_{1}}{O F_{1}}=\frac{O f_{2}}{O F_{2}}=\frac{2}{3}$.

289 Therefore, $\left(O, f_{1}, G, f_{2}\right)$ is a parallelogram, and the half-edge fluxes $290 \quad\left(Q d_{O}^{1}=\int_{O}^{F_{1}}-\boldsymbol{D} \nabla C\right.$ and $\left.Q d_{O}^{2}=\int_{O}^{F_{2}}-\boldsymbol{D} \nabla C\right)$ are

$$
\left(\begin{array}{l}
Q d_{O}^{1} \\
Q d_{O}^{2}
\end{array}\right)=\frac{3}{|E|}\left(\begin{array}{cc}
-\overrightarrow{O F}_{1}^{\perp} \cdot \boldsymbol{D}_{E} \cdot{\overrightarrow{O F_{1}}}^{\perp} & {\overrightarrow{O F_{1}}}^{\perp} \cdot \boldsymbol{D}_{E} \cdot{\overrightarrow{O F_{2}}}^{\perp} \\
{\overrightarrow{O F_{1}}}^{\perp} \cdot \boldsymbol{D}_{E} \cdot{\overrightarrow{O F_{2}}}^{\perp} & -{\overrightarrow{O F_{2}}}^{\perp} \cdot \boldsymbol{D}_{E} \cdot{\overrightarrow{O F_{2}}}^{\perp}
\end{array}\right)\left(\begin{array}{c}
\lambda_{1}-C_{E, 1} \\
\lambda_{2}-C_{E, 1}
\end{array}\right)
$$


where $\boldsymbol{D}_{E}$ is the dispersion tensor of the element $E$, given by equation (4) and using the velocity at the center of $E$ from equations (8) and (9).

294 Equation (18) is written for all elements sharing the vertex O. Then, imposing continuity of 295 half-edge fluxes and continuity of the concentration at the continuity points gives a local 296 system, which we invert to obtain explicitly the concentration at each continuity point as a 297 function of the concentration at all elements sharing the node O. The latter is then replaced in 298 equation (18), and the summation of all half-edge fluxes is then substituted into equation (17) 299 (see [29] for more details). Therefore, the first line of the system (17) contains the 300 contribution of all elements sharing at least one node of the element $E$. The second and third 301 equations of (17) contain the contribution of adjacent elements sharing an edge with $E$. Note 302 that, because of the judicious choice of DOFs, the DG_MPFA scheme reduces to an upwind 303 FV_MPFA scheme by removing the second and third equations of (17) for all mesh elements.

304 The final vector of residuals for the global flow-transport nonlinear system is formed by the 305 system of equations (10), written for the unknown pressure head $T H_{i}$ at the edges, followed 306 by the system of equations (17), written for the three unknown DOFs of the concentration at 307 each element.

\section{$308 \quad 3.3$ The temporal discretization}

309 The coupled nonlinear flow equation (10) and transport equation (17) are written in a single 310 implicit system of ordinary differential equations (ODEs) or differential algebraic equations 311 (DAEs) of the general form:

$$
F\left(t, y, y^{\prime}\right)=0
$$

313 where $\boldsymbol{y}=\left[\left(T H_{i}\right)_{i=1, ., n b_{-} \text {edges }},\left(C_{E, 1}, C_{E, 2}, C_{E, 3}\right)_{E=1, \ldots, n b_{-} \text {elements }}\right]$ is the vector of unknowns formed 
314 by $(i)$ the head traces at all the edges of the mesh (except Dirichlet boundary edges) and (ii)

315 the three DOFs for the concentration at each element of the mesh. This vector reduces to $\boldsymbol{y}=\left[\left(T H_{i}\right)_{i=1, \ldots, n b_{\_} \text {edges }},\left(C_{E, 1}\right)_{E=1, \ldots, n b \_ \text {elements }}\right]$ with only one DOF per element for the

317 concentration in the case of FV (instead of DG) formulation.

318 The system (19) is solved in time using higher-order methods, which are known to be more 319 efficient than lowest-order methods. Indeed, higher-order methods allow larger time steps and 320 less effort in the nonlinear solver compared with the lowest-order methods [45]. Furthermore, 321 higher-order methods are often combined with an efficient automatic time-stepping scheme, 322 which improves the computational efficiency. The time-step size management is optimized to 323 maintain a given temporal discretization error [36, 45-47].

324 Among the integration methods, the Backward Difference Formula (BDF) has good stability 325 properties and is well adapted for time integration of stiff problems [48]. The Fixed Leading 326 Coefficient Backward Difference Formula (FLCBDF) is used in this work via the DASPK 327 solver. The basic idea of the $k^{\text {th }}$-order FLCBDF method is to convert the system $328 F\left(t_{n}, \boldsymbol{y}_{n}, \boldsymbol{y}_{n}^{\prime}\right)=0$ at a given time $t_{n}=t_{n-1}+\underline{h}$ with solution history $\boldsymbol{y}_{n-1}, \ldots, \boldsymbol{y}_{n-k}$ to the system $329 F\left(t_{n}, \boldsymbol{y}_{n}, \hat{a} \boldsymbol{y}_{n}+\hat{\boldsymbol{b}}\right)=0$ where $\hat{\boldsymbol{a}}$ and $\hat{\boldsymbol{b}}$ depend on the step size $\underline{h}$, the order $k$, and the solution 330 history (see [49] for more details).

331 The main advantages of the FLCBDF method are: $(i)$ it avoids the unstable behavior of the 332 interpolated fixed-step methods and (ii) the Newton iteration matrix can be reused for more 333 steps than in a fully variable-step approach $[38,50]$.

334 The Jacobian matrix is evaluated numerically using finite difference approximation. The same 335 Jacobian matrix is used for several time steps to improve efficiency. Furthermore, to reduce 336 drastically the computational time required for the calculation of the Jacobian, sparsity and 
structure of $\boldsymbol{J}$ are provided and the variables are perturbed by group using the column 338 grouping technique (see [51, 52]).

339 The order (up to the fifth-order) of BDF, as well as the time step's size, are optimized to 340 reduce the computational effort while maintaining a small temporal truncation error. The

342 criteria are fixed to $10^{-5}$ in this work.

343 In this work, we use the DASPK time solver with the preconditioned Krylov iterative method 344 to solve the linear systems arising at each time step.

\section{4. Numerical experiments}

346 Three test cases are investigated to show the efficiency and accuracy of the developed 347 numerical model. The first test case is inspired by the laboratory experiment performed by 348 Vauclin et al. [53]. It deals with the infiltration, under constant flux, of a dense contaminant 349 into an unsaturated-saturated porous medium. This test, which is relatively simple from a 350 computational point of view, is used to validate the developed code against a standard finite 351 element solution obtained using COMSOL Multiphysics ${ }^{\circledR}$. The second test case, inspired by 352 the work of Forsyth and Kropinski [54], deals with the infiltration of a dense contaminant in a 353 heterogeneous initially dry soil. The simulated moving sharp front induces high nonlinearity, 354 which makes this computational test cases very challenging. It is used to highlight the 355 efficiency of our newly developed model and to assess the advantages of combining high356 performance numerical methods compared with classical ones implemented in COMSOL. 357 The last test case is investigated to show the applicability of the new model to large-scale 358 problems. In this test case, the developed numerical tool is used to simulate a simplified 359 conceptual 2D model of saltwater intrusion under climate change for the Akkar coastal 360 aquifer in Lebanon. 
Vauclin et al. [53] performed laboratory experiments to investigate the transient position of the water table under artificial recharge. The problem is extended here by including the infiltration from the surface of a dense contaminant and used for the validation of the new

365 model by comparison with COMSOL results. The domain is a rectangular sandbox of $600 \mathrm{~cm}$ $366 \times 200 \mathrm{~cm}$, with the water table located at $65 \mathrm{~cm}$ from the bottom. The initial conditions 367 correspond to hydrostatic pressure distribution with a domain free from pollutants. Infiltration 368 of a contaminant under a constant flux of $86.4 \mathrm{~cm} /$ day is then applied over $200 \mathrm{~cm}$ in the 369 center of the soil surface. A Dirichlet boundary condition with a head of $65 \mathrm{~cm}$ is fixed below 370 the water table. A no-flow boundary is prescribed for the bottom and top surface, except for 371 the infiltration zone. Owing to the symmetry of this problem, only the right-hand side of the 372 domain is modeled with a no-flow boundary imposed along the axis of symmetry. The 373 material properties are given in Table 1.

Table 1. Simulation parameters for the first test case inspired from Vauclin et al. [53].

\begin{tabular}{cc}
\hline Parameters & \\
\hline$\theta_{r}$ & 0.01
\end{tabular}




\begin{tabular}{cc}
$\theta_{s}$ & 0.3 \\
$\alpha\left(\mathrm{cm}^{-1}\right)$ & 0.033 \\
$n$ & 4.1 \\
$K\left(\mathrm{~cm} \cdot \mathrm{s}^{-1}\right)$ & $10^{-2}$ \\
$S_{s}\left(\mathrm{~cm}^{-1}\right)$ & $10^{-10}$ \\
$\alpha_{L}(\mathrm{~cm})$ & 1 \\
$\alpha_{T}(\mathrm{~cm})$ & 0.1 \\
$D_{m}\left(\mathrm{~m}^{2} / \mathrm{s}\right)$ & $10^{-9}$ \\
$\rho_{0}\left(\mathrm{~kg} / \mathrm{m}^{3}\right)$ & 1000 \\
$\rho_{1}\left(\mathrm{~kg} / \mathrm{m}^{3}\right)$ & 1000 or 1100 \\
$\mu\left(\mathrm{kgm}^{-1} \mathrm{~s}^{-1}\right)$ & 0.001 \\
\hline
\end{tabular}

382 The simulation is performed for 80 hours using a triangular mesh formed by 4273 triangular 383 elements. Two configurations are investigated: in the first one, the injected contaminant is a 384 tracer $\left(\rho_{1}=1000 \mathrm{~kg} / \mathrm{m}^{3}\right)$, whereas in the second, the contaminant has a higher density $385\left(\rho_{1}=1100 \mathrm{~kg} / \mathrm{m}^{3}\right)$.

386 The evolution of the contaminant plume during the time for both situations is shown in Figure 387 2. Before reaching the water table (initially at $z=65 \mathrm{~cm}$ ), the tracer and dense contaminant 388 plumes are almost the same (see results at $t=15 \mathrm{~h}$ ). Indeed, density variation seems to have 389 no effect during the transport through the unsaturated zone. The main reasons for this 390 similarity are that $(i)$ a fixed flux is used at the surface and hence the same quantity of 391 contaminant is intruded in the system for both situations and (ii) the density variation in the 392 liquid phase $(10 \%)$ is much less important than the density variation between the liquid and 393 air phase, which is about three orders of magnitude. This last reason is no longer valid once 394 the plume reaches the water table. As a consequence, due to density effects, the dense 395 contaminant moves downward in the saturated domain, creating a recirculation zone (vortex) 396 near the water table interface (see results of Figure 2, at $t=30 \mathrm{~h}$ ), whereas the tracer 
contaminant remains near the water table. The velocity distribution in the unsaturated zone is quite similar for the tracer and dense contaminant situations, whereas strong differences can be observed in the saturated zone. For the tracer contamination, the velocity is not affected by the evolution of the contaminant and remains mainly horizontal. However, in the case of the dense contaminant, strong vertical velocities appear due to density effects, which bring the contaminant down to the bottom. As a consequence, the results in terms of velocity field and contaminant distribution at $t=80 \mathrm{~h}$ for the dense and tracer situations are completely different. The tracer moves mainly horizontally at the upper part of the saturated zone with a maximum displacement near the water table, whereas the dense contaminant moves toward the substratum and then horizontally in the lower part of the domain. The vortex remains near the water table interface (see results of Figure 2 at $t=80 \mathrm{~h}$ ).

408 The validity of the new model is investigated by comparing the obtained results against those 409 of the popular COMSOL model. The same spatial discretization was used to allow for a comparison between COMSOL and our newly developed model, and the solution was also checked on a fine mesh since no analytical solution is available. The results of the two models are almost similar, which demonstrates the validity of the developed model (Figure 3). Notice that the non-dimensional mass injected from the upper boundary during the simulation is 0.288 . With the new numerical model, the total mass in the domain at $80 \mathrm{~h}$ is 0.28815 , whereas it is 0.2820 with COMSOL. Hence, the mass balance error with COMSOL is around 0.021, whereas it is around $5 \times 10^{-4}$ with the new model. Therefore, the very small difference observed in Figure 3 between the isocontour levels of the new model and COMSOL is probably due to the loss of mass observed with COMSOL.

Both COMSOL and the new model were used with the MOL and a variable high-order (up to 5) time integration BDF method. The evolution of the time step's length with the new model during the simulation of the tracer and the dense contaminant infiltration situations are 
depicted in Figure 4. The tracer simulation required 51s of CPU time, for a total number of 1128 time steps. The time step starts at $10^{-4} \mathrm{~s}$ and increases to $1655 \mathrm{~s}$ in almost a monotonic way (see Figure 4a). Only 37 Jacobian evaluations are required during the 1128 time steps. 425 The simulation of the dense contaminant required more CPU time (70 s) and needed more 426 time steps (1751). In this case, smaller time steps are used (the maximum is $389 \mathrm{~s}$ ), and the 427 time step size is no longer monotonic (Figure 4b), probably because of the more complex 428 occurring physics. Note that the evolution of the time step's size remains quite similar before 429 the wetting front reaches the saturated zone. The same Jacobian is maintained for several time 430 steps since the number of evaluations of the Jacobian remains small (only 40 evaluations), 431 which shows the efficiency of the new model.

432 As a comparison, the simulation of the dense contaminant with COMSOL requires 1452 time 433 steps. The evolutions of the time step's length with both models are similar. However, the 434 new model was around 10 times more efficient than COMSOL. Indeed, the new model spent 435 only 70 seconds of CPU time, whereas COMSOL required 720 seconds for the whole 436 simulation. In fact, COMSOL was very slow in the early stages of simulation, probably due to 437 the significant oscillating pressure and concentration values observed in the neighborhood of 438 the infiltration front. These unphysical oscillations affect the convergence of the nonlinear 439 solver and increase the number of nonlinear iterations per time step. 


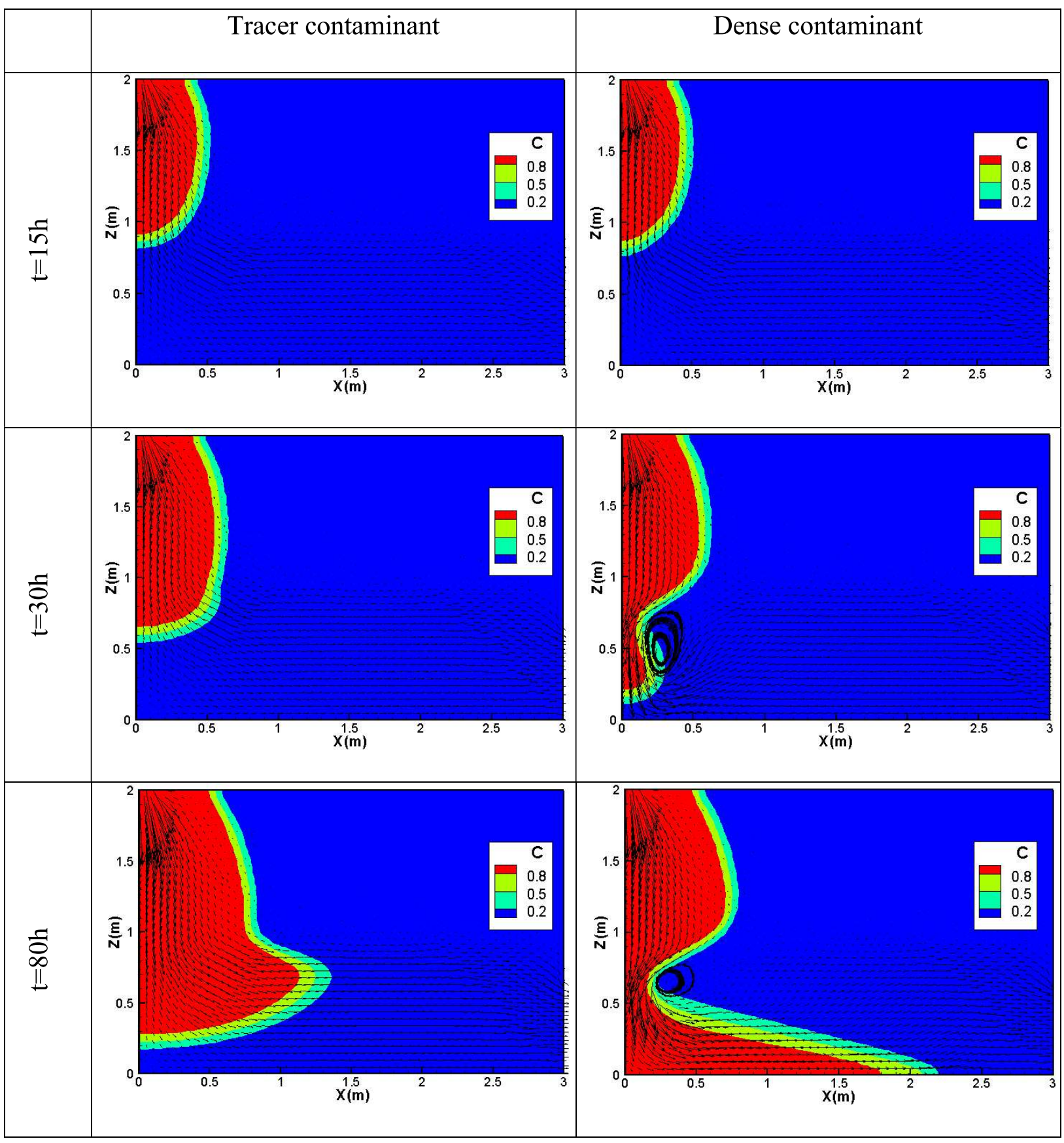

445 Figure 2. velocity field and contaminant distributions for the infiltration of a tracer and a 446 dense contaminant in an unsaturated-saturated system. 


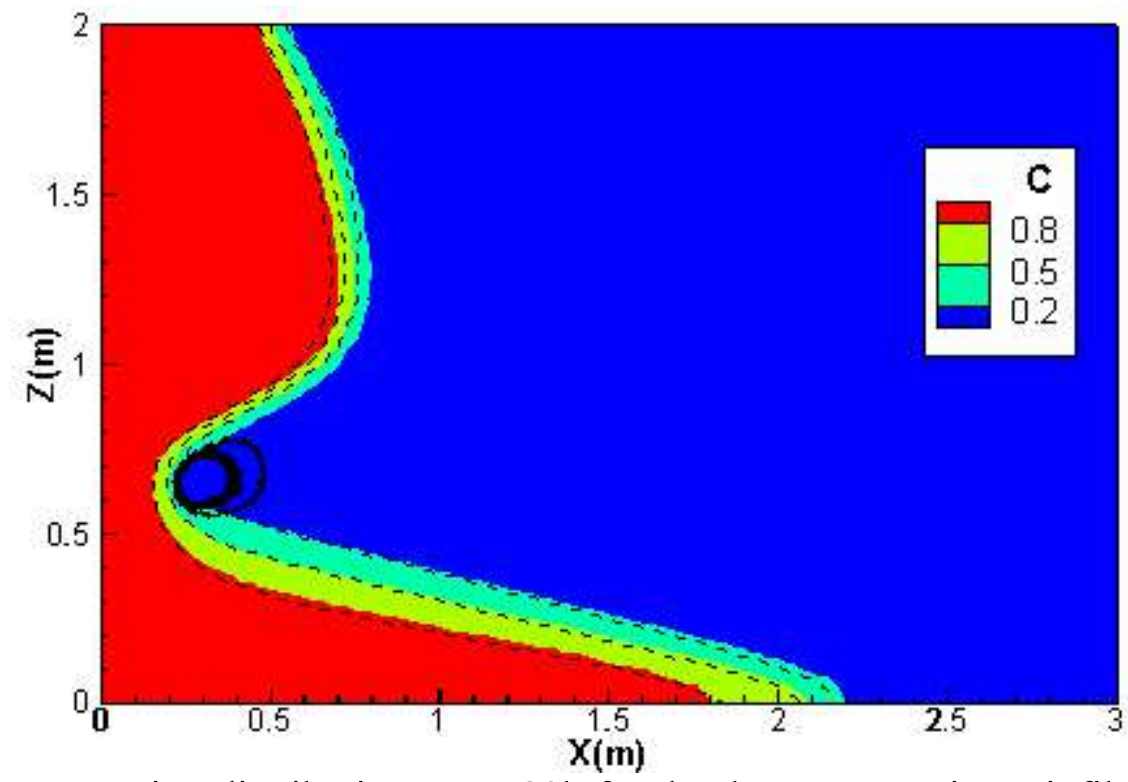

Figure 3. Concentration distribution at $t=80 \mathrm{~h}$ for the dense contaminant infiltration: Results of the new model (contours) versus COMSOL results (dashed-lines)
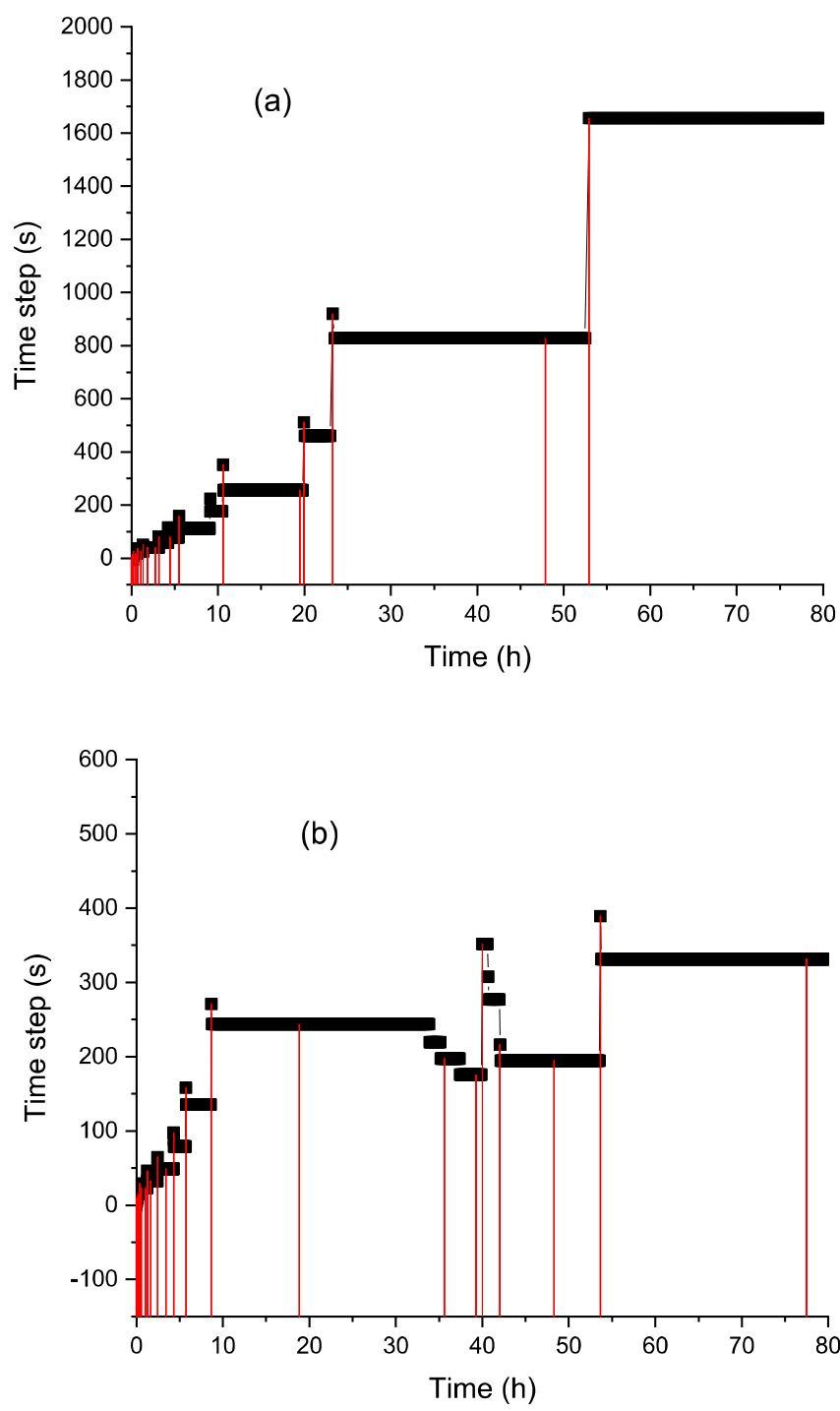

Figure 4. Time step evolution for the tracer (a) and dense (b) contaminant infiltration simulated with the new model. 

4 6457 7

Simulating infiltration into dry soils is known to be a challenging task. Indeed, for very dry conditions, the head gradient becomes extremely large at the wetting front, which can lead to large computational times and unphysical oscillations [20]. To investigate the efficiency of 459 the developed model for such situations, we simulate the infiltration problem given in [36]. 460 The problem is inspired from Huang et al. [55] and involves infiltration under a constant head 461 boundary condition into a heterogeneous dry soil. The domain has a rectangular shape of 125 $462 \mathrm{~cm}$ width and $230 \mathrm{~cm}$ depth and contains two horizontal layers. The surface layer of $40 \mathrm{~cm}$ 463 thickness is formed by a clayey soil. The subsurface layer is a sandy soil of $190 \mathrm{~cm}$ thickness. 464 The properties of the two soil layers are depicted in Table 2. A Dirichlet boundary condition 465 is prescribed in the strip $0 \leq x \leq 20 \mathrm{~cm}$ at the surface with a fixed pressure head of $-10 \mathrm{~cm}$. A 466 fixed pressure head of $-10^{4} \mathrm{~cm}$ is maintained at the bottom of the domain. The other sides are 467 impervious. A constant initial pressure head of $-10^{4} \mathrm{~cm}$ is considered for the entire domain, 468 which corresponds to an initial water content of $0.059 \mathrm{~cm}^{3} \cdot \mathrm{cm}^{-3}$ and $0.045 \mathrm{~cm}^{3} \cdot \mathrm{cm}^{-3}$, 469 respectively, in the upper and lower layer. The infiltrated contaminant has a density of $4701025 \mathrm{~kg} \cdot \mathrm{m}^{-3}$, which corresponds to seawater density. A triangular mesh of 3505 elements is 471 used for the spatial discretization, and the final simulation time is 7 days. 
Table 2. Simulation parameters for the problem of contaminant infiltration in a heterogeneous initial dry soil.

\begin{tabular}{ccc}
\hline Parameters & Upper Layer & Lower Layer \\
\hline$\theta_{r}$ & 0.0001 & 0.045 \\
$\theta_{s}$ & 0.40 & 0.43 \\
$\alpha\left(\mathrm{cm}^{-1}\right)$ & 0.0174 & 0.145 \\
$n$ & 1.37 & 2.68 \\
$K\left(\times 10^{-4}{\left.\mathrm{~cm} \cdot \mathrm{s}^{-1}\right)}^{-10}\right.$ & 3.5 & 82.5 \\
$S_{s}\left(\times 10^{-10} \mathrm{~cm}^{-1}\right)$ & 1 & 1 \\
$\alpha_{L}(\mathrm{~cm})$ & 0.5 & 0.5 \\
$\alpha_{T}(\mathrm{~cm})$ & 0.1 & 0.1 \\
$D_{m}\left(\mathrm{~m}^{2} / \mathrm{s}\right)$ & $10^{-9}$ & $10^{-9}$ \\
$\rho_{0}\left(\mathrm{~kg} / \mathrm{m}^{3}\right)$ & 1000 & 1000 \\
$\rho_{1}\left(\mathrm{~kg}^{3} \mathrm{~m}^{3}\right)$ & 1025 & 1025 \\
$\mu\left(\mathrm{kgm}^{-1} \mathrm{~s}^{-1}\right)$ & 0.001 & 0.001 \\
\hline
\end{tabular}

479 The obtained pressure and concentration distributions are shown in Figure 5. In this figure, 480 the pressure shows a sharp front, reflecting a very high gradient caused by the dry initial 481 conditions $(-100 \mathrm{~m})$.
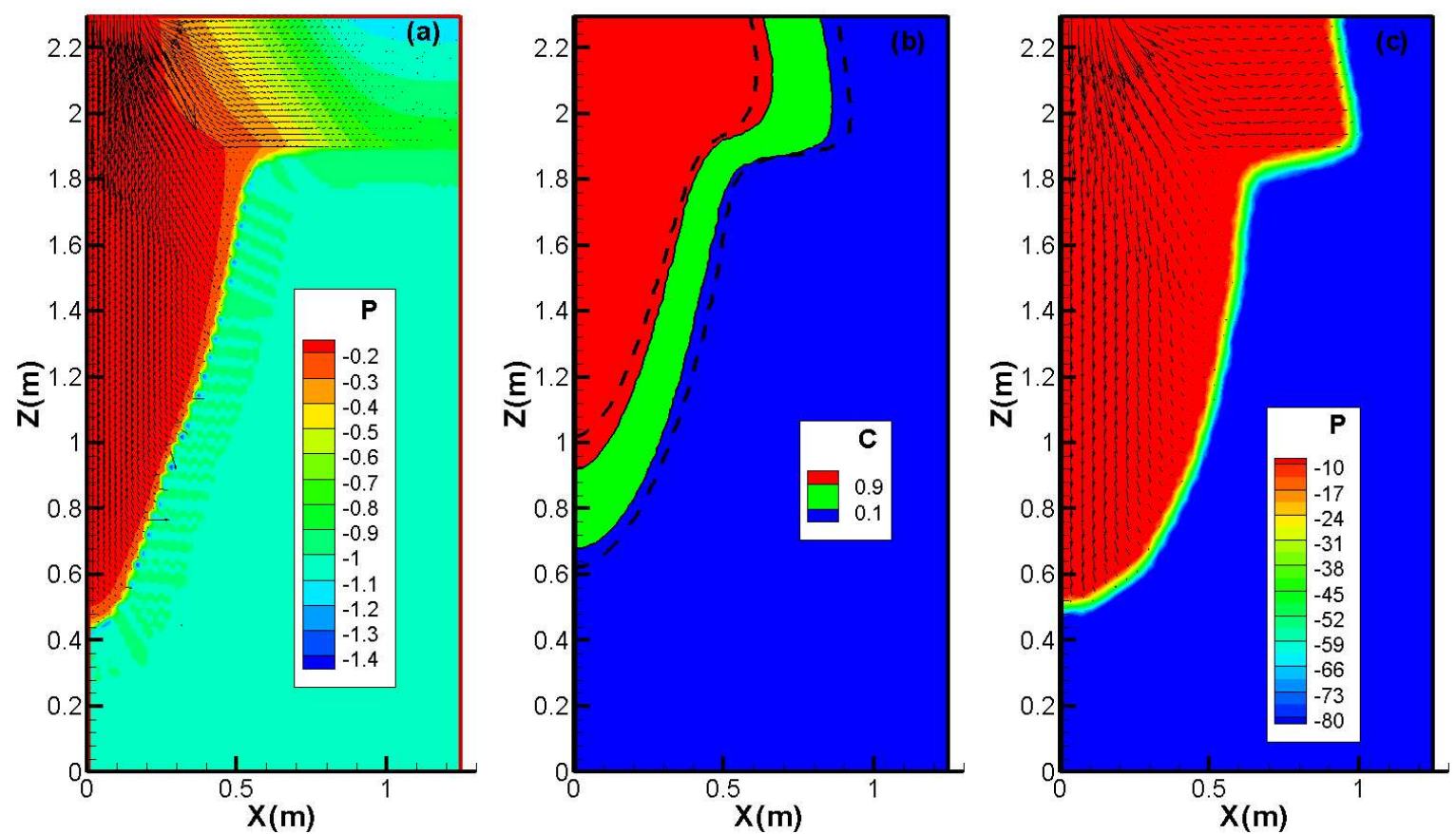

Figure 5. (a) Pressure distribution (in $\mathrm{m}$ ) with COMSOL, (b) pressure and (c) concentration distributions with the new model at $\mathrm{t}=7$ days for the problem of contaminant infiltration in a heterogeneous initial dry soil. Dashed lines represent results of upwind first order FV instead of DG for advection. 
The sharp pressure front cannot be accurately simulated with COMSOL. Indeed, the

simulation of this test case with COMSOL using the same mesh failed to converge because of unphysical oscillations generated near the wetting interface. Convergence problems have been also encountered when changing the initial (and bottom) conditions from $-100 \mathrm{~m}$ to $-1 \mathrm{~m}$. The only way to obtain a convergent solution with COMSOL was to use a finer mesh of about 14,000 elements and an initial pressure head of $-1 \mathrm{~m}$ instead of $-100 \mathrm{~m}$. And, even for such a situation, the results of COMSOL are inaccurate since the obtained pressure head is between $1.4 \mathrm{~m}$ and $-0.1 \mathrm{~m}$ instead of $-1 \mathrm{~m}$ and $-0.1 \mathrm{~m}$. Besides, the solution contains strong unphysical oscillations near the wetting interface (Figure 5a). These unphysical oscillations are avoided with the new code, thanks to the used advanced numerical methods and, especially, the mass lumping procedure, which avoids unphysical oscillations in the case of transient simulations with sharp wetting fronts $[27,28]$.

500 Figure $5 \mathrm{c}$ shows the final concentration distribution at $t=7$ days. The results of a simplified 501 version of the numerical code using the upwind first-order FV scheme instead of DG are also 502 depicted (dashed lines) in Figure 5c. This figure shows that a large numerical diffusion is 503 generated using the upwind first-order FV method. To quantify the difference between the 504 two methods, the spread of the concentration $L_{S}=X_{0.9}-X_{0.1}$, corresponding to the distance 505 between the $10 \%$ and $90 \%$ isochlors at the left vertical side of the domain, is measured for the $506 \mathrm{FV}$ and DG simulations. The spread with FV is $L_{S}{ }^{F V}=0.4$, whereas with DG, it is $507 L_{S}{ }^{D G}=0.24$. Hence, due to numerical diffusion, the spread with the FV method is around $508170 \%$ that of DG. This shows clearly that DG is well-adapted for advective-dominated 509 transport and generates limited numerical diffusion compared with the upwind first-order FV 510 method.

511 It is worth noting that, in the first test case, the contaminant distribution in the unsaturated 
512 region was not affected by the density of the contaminant, since the infiltration occurred under

\section{Time integration} method

a constant flux boundary condition. For the current test case, the concentration distribution is sensitive to the density of the contaminant because of the Dirichlet boundary condition used at the surface infiltration boundary (results are not shown in the paper). The pollutant infiltration is slightly more pronounced with the dense contaminant than with the tracer contaminant. The total mass in the system at $t=7$ days is $0.64 \mathrm{~kg}$ with the tracer, whereas it is $0.66 \mathrm{~kg}$ if the contaminant has a density of $1025 \mathrm{~kg} \cdot \mathrm{m}^{-3}$. This total mass can increase up to $0.76 \mathrm{~kg}$ in the case of a contaminant with a density of $1200 \mathrm{~kg} \cdot \mathrm{m}^{-3}$ (brine contamination).

Finally, to highlight the benefit of the higher-order time integration for the investigated challenging infiltration problem, we compare the efficiency of the model when used with a first-order and with a variable high-order (up to 5) time integration with the BDF method.

Table 3. Performance statistics for the first-order and variable order methods implemented in the advanced developed model for the simulation of the second test case.

\begin{tabular}{cccccc}
\hline $\begin{array}{c}\text { Time integration } \\
\text { method }\end{array}$ & CPU & $\begin{array}{c}\text { Nb } \\
\text { time steps }\end{array}$ & $\begin{array}{c}\text { Nb } \\
\text { Jacobian }\end{array}$ & $\begin{array}{c}\text { Max } \\
\text { time step }\end{array}$ & $\begin{array}{c}\text { Mean } \\
\text { time step }\end{array}$ \\
\hline $\begin{array}{c}\text { First-order } \\
\text { Variable-order } \\
\text { (up to 5) }\end{array}$ & 896 & 28871 & 115 & 45 & 21 \\
\hline
\end{tabular}

526 The results of Table 3 show that the high-order method requires more Jacobian evaluations, 527 but allows much larger time steps and needs fewer calculations compared with the classical 528 first-order method. The variable high-order method is around 7 times more efficient than the 529 first-order method for the investigated problem.

\subsection{Large-scale simulation of SWI under climate change}

531 The developed numerical tool is used to simulate a large-scale contamination problem with 532 large spatial and temporal ranges that occurs in the Akkar unconfined coastal aquifer, located 
533 in the north of Lebanon (Figure 6a). The plain is cultivated with market gardening and cereals 2534 crops and the aquifer underwent a significant increase in pumping water, both for irrigation 

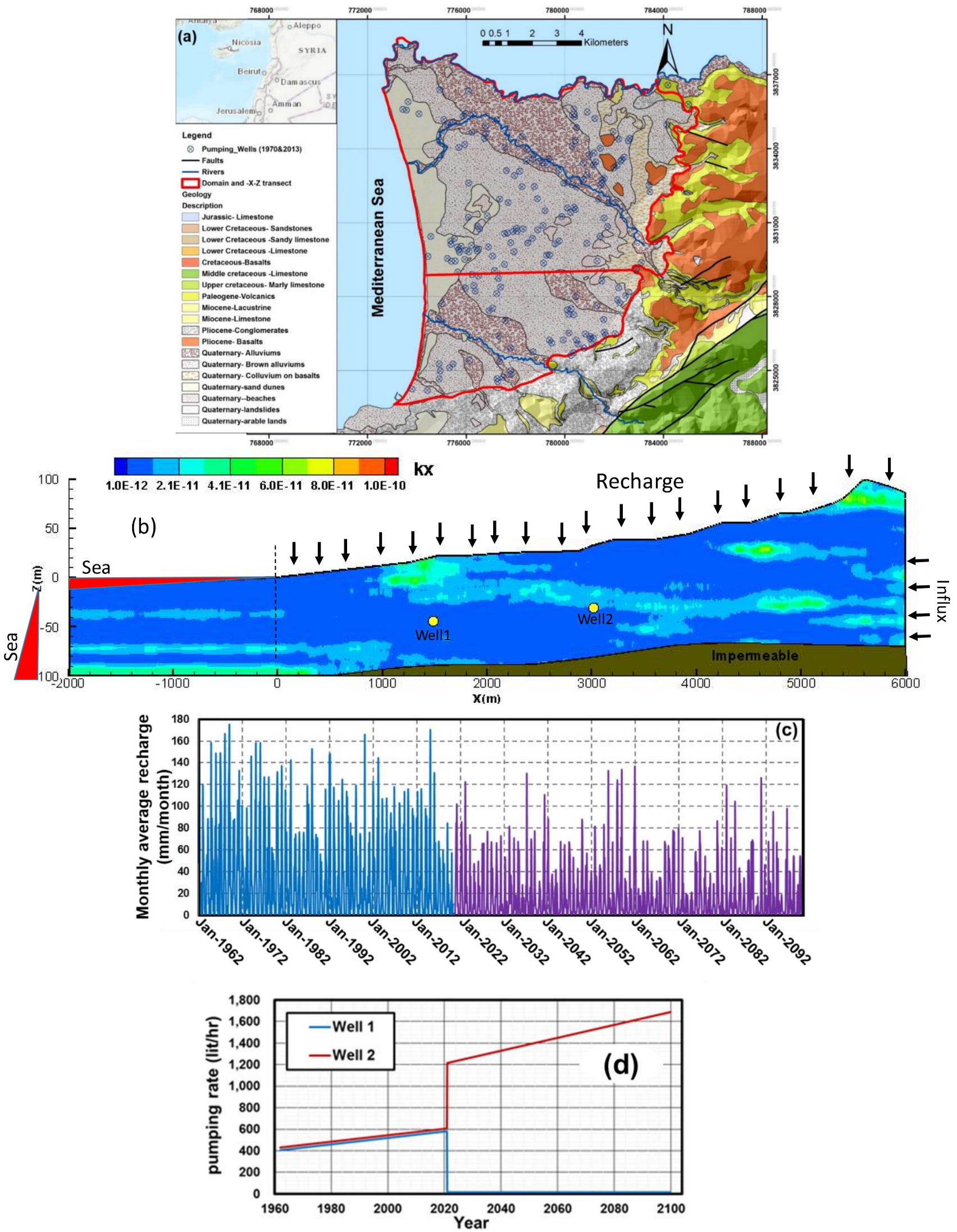

551 Figure 6. (a) Location of the Akkar aquifer, (b) conceptual representation of the aquifer with a lognormal permeability field and the boundary conditions (c) the recharge data until 2019 and projections under climate change between 2020 and 2099 and (d) pumping rates in production wells. 
555 The shore-perpendicular section has an extension of $2 \mathrm{~km}$ offshore and $6 \mathrm{~km}$ onshore [56]. 556 The depth of the Akkar basin varies between $100 \mathrm{~m}$ and $170 \mathrm{~m}$ from the surface and is formed by fluvial deposits. In the conceptual model (Figure 6b), the permeability field was generated assuming a lognormal distribution with a variance of $1.0 \mathrm{~m}^{4}$ and a geometric average conductivity of $0.94510^{-11} \mathrm{~m}^{2}$. An exponential correlation function was used with horizontal and vertical correlation lengths of $1000 \mathrm{~m}$ and $10 \mathrm{~m}$, respectively. The bottom is formed by clays and marls and is considered impermeable. The left vertical side corresponds to the sea boundary, which has a prescribed concentration of $C=35 \mathrm{~g} . \mathrm{l}^{-1}$ and a vertical hydrostatic pressure distribution. The recharge, depicted in Figure 6c, corresponds to observed data for the period between 1962 and 2020 and a projection for the period 2020-2099, obtained from the IPSL_CM5 Global Climate Model (GCM) [57]. A weak regional flow is assumed at the right land boundary. Although radial upconing around wells have necessarily 3D configurations, two wells are assumed to represent the different pumping activities in the Akkar aquifer [58]. The wells are located at, respectively, $1500 \mathrm{~m}$ and $3000 \mathrm{~m}$ from the shoreline at, respectively, a depth of $45 \mathrm{~m}$ and $30 \mathrm{~m}$. The rates for the two pumping wells (Figure 6d) are assumed to represent the observed rates for the period 1962-2020 and expected rates (with increasing water demand) for 2020-2099. Note that pumping was stopped for Well 1 (the closest to the sea) in 2020 because of salinization. The pumping rate of Well 1 was transferred to Well 2. 
579 Table 4. Properties of the soil and the water for the simulation of the simplified conceptual 1580 Akkar aquifer.

582 The domain is discretized with approximately $75 \mathrm{~K}$ triangular elements with an almost equal

\begin{tabular}{|c|c|}
\hline Parameter & Value \\
\hline Freshwater density $\rho_{0}\left(\mathrm{~kg} \cdot \mathrm{m}^{-3}\right)$ & 1,000 \\
\hline Seawater density $\rho_{1}\left(\mathrm{~kg} \cdot \mathrm{m}^{-3}\right)$ & 1,025 \\
\hline Gravity $g\left({\left.\mathrm{~m} \cdot \mathrm{s}^{-2}\right)}^{-1}\right)$ & 9.81 \\
\hline Viscosity $\mu\left(\mathrm{kg} \cdot \mathrm{m}^{-1} \cdot \mathrm{s}^{-1}\right)$ & $10^{-3}$ \\
\hline Anisotropy ratio $r_{k}\left(=k_{z} / k_{x}\right)$ & 0.1 \\
\hline Porosity $\varepsilon$ & 0.39 \\
\hline Storage coefficient $S_{s}\left(\mathrm{~m}^{-1}\right)$ & $5 \times 10^{-4}$ \\
\hline Molecular diffusion $D_{m}\left(\mathrm{~m}^{2} \cdot \mathrm{s}^{-1}\right)$ & $1.0 \times 10^{-9}$ \\
\hline$\alpha(\mathrm{cm})$ & 0.01 \\
\hline$n$ & 1.75 \\
\hline$\theta_{s}$ & 0.39 \\
\hline$\theta_{r}$ & 0.1 \\
\hline$\alpha_{L}(\mathrm{~m})$ & 5 \\
\hline$\alpha_{T}(\mathrm{~m})$ & 0.5 \\
\hline $\begin{array}{c}\text { Right boundary condition: Regional } \\
\text { flow/ unit width } q_{d}\left(\mathrm{~m}^{2} \cdot \mathrm{s}^{-1}\right)\end{array}$ & $6 \times 10^{-7}$ \\
\hline
\end{tabular}

area of $15 \mathrm{~m}^{2}$. The simulation is, at first, performed for a long time with the yearly average recharge of pre-1962, without pumping to mimic the natural equilibrium conditions (Figure 7a). The value of recharge for this period is taken uniformly and equal to $90 \mathrm{~mm} \cdot \mathrm{y}^{-1}$. Next, two periods are simulated: $(i)$ the $1962-2020$ period, which leads to the current situation of the coastal aquifer (Figure 7b), and (ii) the 2020-2099 period, which corresponds to the future response of the aquifer to the impact of a climate change projection and estimated pumping regime (Figure 7c).

The problem is solved for 333,031 DOFs (unknowns) on a computer with a single Intel i77700 processor $3.6 \mathrm{GHz}$ and 16 Go of RAM (i.e. Random Access Memory). The whole simulation (138 years) required around 9h of CPU time. 

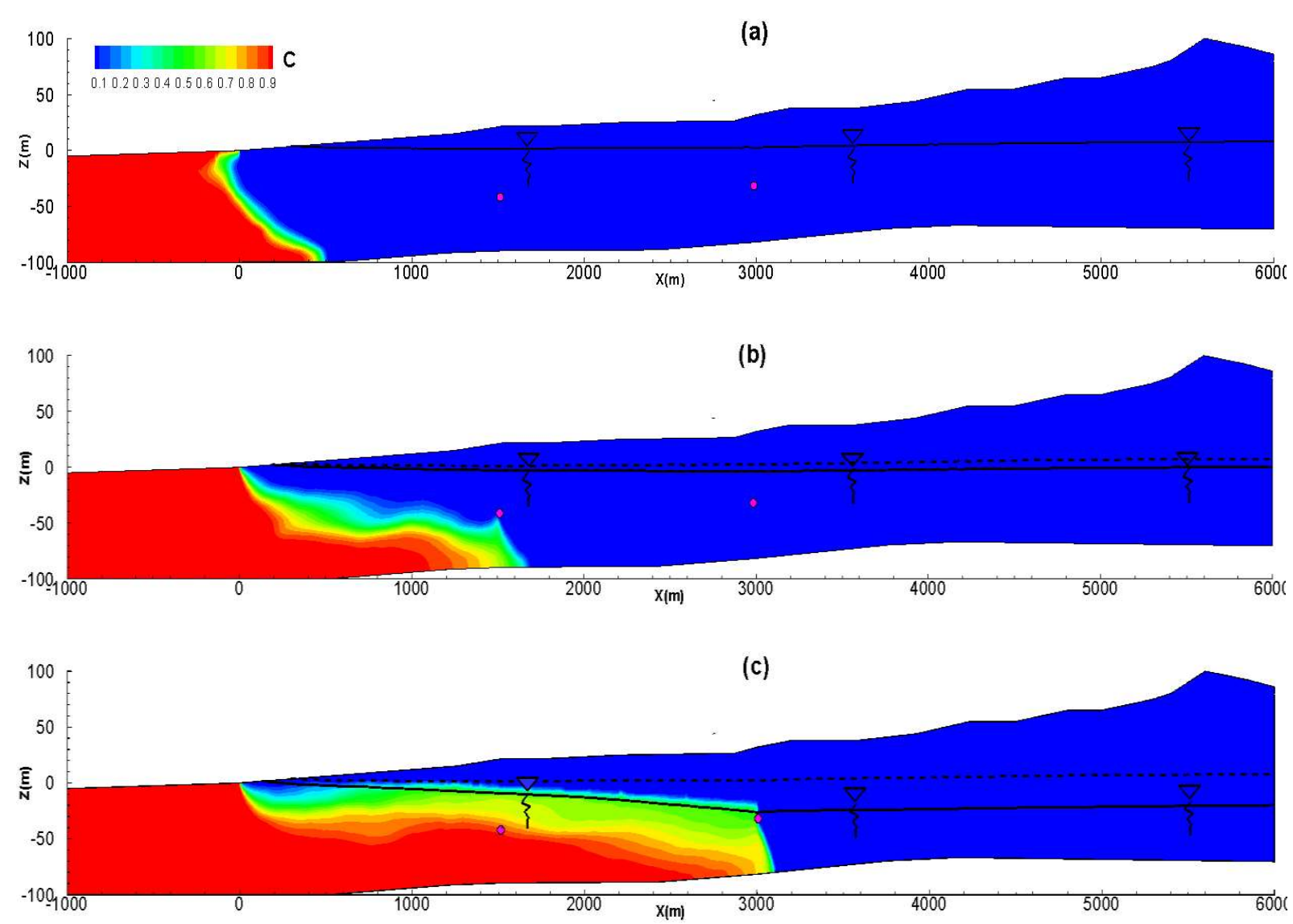

597 Figure 7. Spatial salinity distribution in the aquifer and water table position: (a) at 1962 (state 598 of equilibrium), (b) currently at 2020 and (c) predictions for 2099.

600 Figure 7 a shows that, without any pumping, the natural equilibrium situation of 1962 shows a 601 moderate saltwater intrusion. The concentration profile shows a small dispersion. The aquifer 602 is only contaminated near the bottom, for a distance of around $400 \mathrm{~m}$ from the shoreline. 603 Because of pumping, the concentration distribution at 2020 shows a more significant saltwater 604 intrusion. In Figure $7 \mathrm{~b}$, Well 1, located $1500 \mathrm{~m}$ from the shoreline, is reached by salt 605 contamination, which is in agreement with the field observations. The breakthrough curves of 606 salt concentration at the two wells are depicted in Figure 8. In this figure, a small inflection is 607 observed in 2020 when pumping is stopped at Well 1. Then, the concentration continues to 608 increase because of the advancement of the salt front caused by the pumping in Well 2. The 609 final concentration in Well 1 is very high and reaches 30 g. $1^{-1}$. Well 2, located $3000 \mathrm{~m}$ from 
610 the shoreline, starts to be salinized at around 2060. Then, the concentration continues to 1

2611 increase significantly, with a high rate of salinization, which makes the well unusable in 2070 612 and onward. 


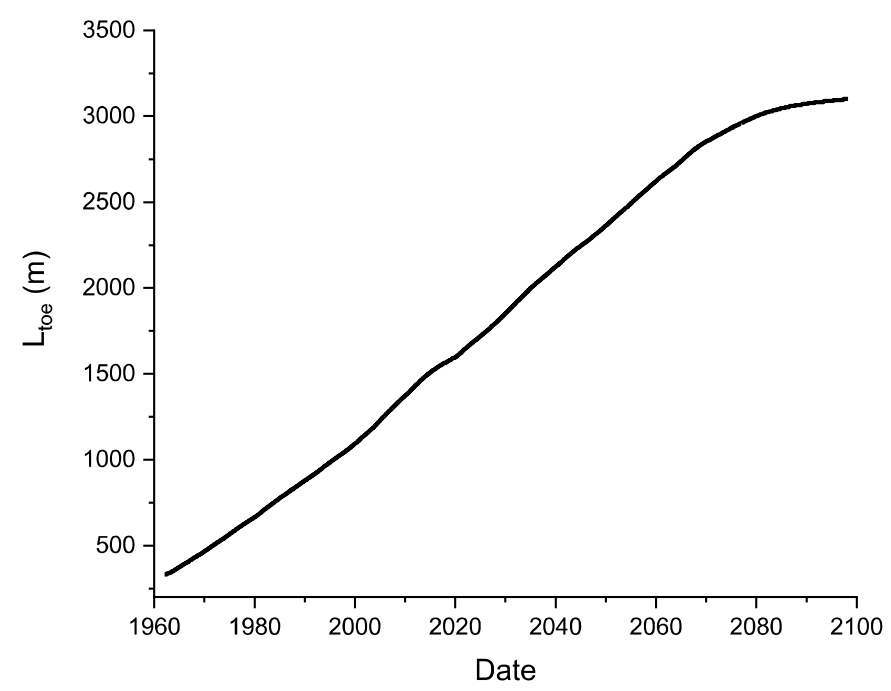

627 Figure 9. Evolution of $\mathrm{L}_{\text {toe }}$ (the maximum horizontal distance between the shoreline and the $62850 \%$ salt concentration contour).

630 Finally, note that the predicted state in 2100 (Figure 7c) shows that a significant water table 631 falls more than $20 \mathrm{~m}$, which warrants the use of that saturated-unsaturated model to 632 investigate problems of density-driven flow in unconfined coastal aquifers.

\section{5. Conclusion}

634 Unsaturated-saturated aquifer systems can be subject to pollution by dense contaminants such 635 as SWI in coastal unconfined aquifers. Modeling such problems requires the solution of a 636 highly nonlinear system combining the nonlinear Richards' equation with the advection637 dispersion transport equation. The solution of such a nonlinear system can be hampered by 638 convergence issues and excessive computational time, especially for regional-scale problems. 639 A new model has been developed in this work based on advanced spatial discretization 640 methods (lumped MHFE, implicit DG and MPFA methods) and higher-order time integration 641 techniques via the method of lines.

642 The efficiency and accuracy of the new model have been investigated for three test cases. The 643 first test case deals with the infiltration of a contaminant in an unsaturated-saturated 
644 rectangular sandbox. This test case served as a benchmark to validate the numerical model. 2645 The results of simulations are similar to those obtained with COMSOL. Tracer and dense 646 7 8 contaminants yielded similar plumes in the unsaturated zone. However, when the water table is reached, the dense contaminant moves downward, creating a recirculation zone, whereas the tracer moves horizontally along the water table. The test case shows that the new model is highly efficient since it uses large time steps and maintains the same Jacobian for several calculations.

The second test case deals with the challenging problem of infiltration into a heterogeneous and initially very dry soil. For this problem, COMSOL failed to reproduce the sharp pressure front and generated strong unphysical oscillations. The new model gives accurate results, and the higher-order integration method is around 7 times more efficient than the classical firstorder method.

Finally, the developed model has been used to simulate a simplified 2D conceptual model of SWI in the Akkar unconfined aquifer, under climate change and long-term pumping regimes. The purpose of this last test case was to show the applicability of the newly developed model in simulating large-scale regional problems under dynamic conditions. The results show that SWI was moderate in the case of natural equilibrium (in 1962). Then, because of the pumping undergone in the past decades, a significant SWI occurred and salinization reached the pumping well at $1500 \mathrm{~m}$. Simulations until 2100 show that the reduced recharge caused by climate change and the increase in pumping due to the evolution of water demand induce significant salinization of the aquifer, with a salt front advancing inland at an average speed of $25 \mathrm{~m} \cdot \mathrm{y}^{-1}$ and an important water table fall. Note that these preliminary results must be taken with caution since the simulations were performed on a simplified 2D conceptual model without any calibration because of the lack of data. 
668 This study points out that the newly developed numerical model is an interesting tool to assess 1

2669 environmental issues. Efficient and robust numerical models are useful for applications at 670 large scales, involving repetitive simulations, as in model calibration, sensitivity/uncertainty 671 analysis, and scenario-based studies.

\section{Acknowledgments}

674 The authors wish to thank the Investissements d'Avenir and ADEME for supporting this work 1767 18 
2680

681

682

683

684

685

686

687

688

689

690

691

692

693

694

695

696

697

698

699

700

701

702

703

704

705

706

707

708

709

710

711

712

713

714

715

716

717

718

719

720

721

722

723

724

725

726

727

[1] Diersch, H.J., Kolditz, O., 2002. Variable-density flow and transport in porous media: approaches and challenges. Advances in Water Resources 25, 899-944.

[2] Simmons, C.T., 2005. Variable-density groundwater flow: From current challenges to future possibilities. Hydrogeology Journal 13, 116-119.

[3] Graf, T., Simmons, C.T., Boufadel, M.C., Neuweiler, I., 2010. Movement of dense plumes in variably saturated porous media: numerical model and results. Proceedings of the XVIII International Conference on Water Resources (CMWR), Barcelona, Spain, June 2010. Abstract 23.

[4] Werner, A.D., Bakker, M., Post, V.E.A., Vandenbohede, A., Lu, C., Ataie-Ashtiani, B., et al., 2013. Seawater intrusion processes, investigation and management: Recent advances and future challenges. Advances in Water Resources, 51, 3-26.

[5] Simmons, C.T., Pierini, M.L., Hutson, J.L., 2002. Laboratory investigation of variable density flow and solute transport in unsaturated-saturated porous media. Transport in Porous Media, 47, 215-244.

[6] Oostrom, M., Hayworth, J. S., Dane, J. H. and Guven, O., 1992. Behaviour of dense aqueous phase leachate plumes in homogeneous porous media. Water Resources Research 28(8), 2123-2134.

[7] Dane, F.H., Guven, O., Oostrom, M., Hayworth, J. S. and Leijnse, A., 1994. Dense aqueous phase contaminant plume behaviour in porous media near the groundwater table. IAHS Publ. 222,333-340.

[8] Ouyang, Y., Zheng, C., 1999. Density-driven transport of dissolved chemicals through unsaturated soil, Soil Science 164(6), 376-390.

[9] Boufadel, M.C., Suidan, M.T. and Venosa, A.D., 1999. Numerical modeling of water flow below dry salt lakes: effect of capillarity and viscosity. Journal of Hydrology 221, $55-74$.

[10] America, I., Zhang, C., Werner, A. D., \& van der Zee Sjoerd E. A. T. M. (2020). Evaporation and salt accumulation effects on riparian freshwater lenses. Water Resources Research, 56, e2019WR026380. https://doi.org/10.1029/2019WR026380

[11] Werner, A.D., Lockington, D.A., 2004. The potential for soil salinization above aquifers impacted by seawater intrusion, in Proceedings of 13th International Soil Conservation Organisation Conference: Conserving Soil and Water for Society: Sharing Solutions, edited by S. R. Raine et al., 6 pp., ASSSI/IECA, Brisbane.

[12] Werner, A.D., Lockington, D.A., 2006. Tidal impacts on riparian salinities near estuaries. Journal of Hydrology 328, 511-522.

[13] Ibrahimi, M.K., Miyazaki, T., Nishimura, T., Imoto, H., 2014. Contribution of shallow groundwater rapid fluctuation to soil salinization under arid and semiarid climate. Arabian Journal of Geosciences 7, 3901-3911.

[14] Badaruddin, S., Werner, A.D., Morgan, L.K., 2015. Water table salinization due to seawater intrusion. Water Resources Research 51, 8397-8408.

[15] Qu, W., Li, H., Wan, L., Wang, X., Jiang, X., 2014. Numerical simulations of steadystate salinity distribution and submarine groundwater discharges in homogeneous anisotropic coastal aquifers, Advances in Water Resources. 74, 318-328.

[16] Zhou, P., Li, G., Lu, Y., Li, M., 2014. Numerical modeling of the effects of beach slope on water-table fluctuation in the unconfined aquifer of Donghai Island, China. Hydrogeology Journal 22, 383-96.

[17] Ataie-Ashtiani, B., Volker, R.E., Lockington D.A., 2001. Tidal effects on groundwater dynamics in unconfined aquifers. Hydrological Processes 15, 655-69. 
[18] Farthing, M.W., Ogden, F.L., 2017. Numerical Solution of Richards' Equation: A Review of Advances and Challenges. Soil Science Society of America Journal 81, 1257.

[19] Szymkiewicz, A., 2013. Modelling Water Flow in Unsaturated Porous Media, GeoPlanet: Earth and Planetary Sciences. Springer Berlin Heidelberg, Berlin, Heidelberg.

[20] Zha, Y., Yang, J., Yin, L., Zhang, Y., Zeng, W., Shi, L., 2017. A modified Picard iteration scheme for overcoming numerical difficulties of simulating infiltration into dry soil. Journal of Hydrology 551, 56-69.

[21] Durlofsky, L., 1994. Accuracy of mixed and control volume finite element approximations to darcy velocity and related quantities. Water Resources Research 30(4), 965-974.

[22] Schneider, M., Glaser, D., Flemisch, B., Helmig, R., 2018. Comparison of finite-volume schemes for diffusion problems. Oil \& Gas Science and Technology - Rev. IFP Energies nouvelles 73, 82.

[23] Konz, M., Ackerer, P., Younes, A., Huggenberger, P., Zechner, E., 2009. 2D Stable Layered Laboratory-scale Experiments for Testing Density-coupled Flow Models. Water Resources research 45,W02404.

[24] Younes, A., Ackerer, P., 2010. Empirical vs. time stepping with embedded error control for density-driven flow in porous media. Water Resources research 46(8).

[25] Chavent, G., Roberts, J.-E., 1991. A unified physical presentation of mixed, mixedhybrid finite element method and standard finite difference approximations for the determination of velocities in water flow problems. Advances in Water Resources 14(6), 329-348.

[26] Younes, A., Ackerer, P., Delay, F., 2010. Mixed finite element for solving 2D diffusiontype equations. Reviews of Geophysics, 48(1).

[27] Younes, A., Ackerer, P., Lehmann, F., 2006. A new mass lumping scheme for the mixed hybrid finite element method. International Journal for Numerical Methods in Engineering 67(1), 89-107.

[28] Belfort, B., Ramasomanan, F., Younes, A., Lehmann, F., 2009. An efficient Lumped Mixed Hybrid Finite Element Formulation for variably saturated groundwater flow. Vadose Zone Journal. 8, 352-362.

[29] Younes, A., Ackerer, P., 2008. Solving the Advection-Dispersion Equation with Discontinuous Galerkin and Multipoint Flux Approximation methods on unstructured meshes. International Journal for Numerical Methods in Fluids 58(6), 687-708.

[30] Siegel, P, Mosé, R, Ackerer, P, Jaffré, J., 1997. Solution of the advection-diffusion equation using a combination of discontinuous and mixed finite elements. International Journal for Numerical Methods in Fluids 24, 595-613.

[31] Ackerer, P., Younes, A., Mosé, R., 1999. Modelling variable density flow and solute transport in porous medium: 1. Numerical model and verification. Transport in Porous Media 35, 345-373.

[32] Hoteit, H., Firoozabadi, A., 2005. Multicomponent fluid flow by discontinuous Galerkin and mixed methods in unfractured and fractured media. Water Resources Research. 41(11).

[33] Aavatsmark, I., Barkve, T., Bøe, O., \& Mannseth, T., 1998. Discretization on unstructured grids for inhomogeneous, anisotropic media. Part I: Derivation of the methods. SIAM Journal on Scientific Computing 19(5), 1700-1716.

[34] Younes, A., Fontaine, V., 2008. Hybrid and Multi Point Formulations of the Lowest Order Mixed Methods for Darcy's Flow on Triangles. International Journal for Numerical Methods in Fluids 58(9), 1041-1062. 
[35] Ackerer, P., Younes, A., 2008. Efficient approximations for the simulation of density driven flow in porous media. Advances in Water Resources 31(1), 15-27.

[36] Fahs, M., Younes, A., Lehmann, F., 2009. An easy and efficient combination of the Mixed Finite Element Method and the Method of Lines for the resolution of Richards' Equation. Environmental Modelling \& Software 24(9), 1122-1126.

[37] Younes, A., Fahs, M., Ahmed, S., 2009. Solving density driven flow problems with efficient spatial discretizations and higher-order time integration methods. Advances in Water Resources 32(3), 340-352.

[38] Van Keken, P.E., Yuen, D.A., Petzold, L.R., 1995. DASPK: A new high order and adaptive time-integration technique with applications to mantle convection with strongly temperature-and pressure-dependent rheology. Geophysical \& Astrophysical Fluid Dynamics 80(1-2), 57-74.

[39] van Genuchten, M.Th., 1980. A Closed-form Equation for Predicting the Hydraulic Conductivity of Unsaturated Soils. Soil Science Society of America Journal 44(5), 892898.

[40] Mualem, Y., 1976. A new model for predicting the hydraulic conductivity of unsaturated porous media. Water Resources Research 12, 513-522.

[41] Raviart, P.A., Thomas, J.M., 1977. A mixed finite element method for second order elliptic problems, in Mathematical Aspects of Finite Element Method. Lecture Notes in Mathematics 606, 292-315.

[42] Younes, A., Ackerer, P., Chavent, G., 2004. From mixed finite elements to finite volumes for elliptic PDE in 2 and 3 dimensions. International Journal for Numerical Methods in Engineering, 59, 365-388.

[43] Moortgat, J., Firoozabadi, A., 2016. Mixed-hybrid and vertex-discontinuous-Galerkin finite element modeling of multiphase compositional flow on 3D unstructured grids. Journal of Computational Physics 315, 476-500.

[44] Vohralík, M., 2006. Equivalence between lowest-order mixed finite element and multipoint finite volume methods on simplicial meshes. Mathematical Modelling and Numerical Analysis 40 (2), 367-391.

[45] Farthing, M.W., Kees, C.E., Miller, C.T., 2002. Mixed finite element methods and higher-order temporal approximations. Advances in Water Resources 25, 85-101.

[46] Tocci, M.D., Kelly, C.T., Miller, C.T., 1997. Accurate and economical solution of the pressure-head form of Richards' equation by the method of lines. Advances in Water Resources 20, 1-14.

[47] Kavetski, D., Binning, P., Sloan, S.W., 2001. Adaptative backward Euler time stepping with truncation error control for numerical modelling of unsaturated fluid flow. International Journal for Numerical Methods in Engineering 53,1301-1322.

[48] Kees, C.E., Miller, C.T., 2002. Higher order time integration methods for two-phase flow. Advances in Water Resources 25(2), 159-177.

[49] Brenan KE, Campbell SL, Petzold LR., 1996. The numerical solution of initial value problems in differential-algebraic equations. Philadelphia, PA: Society for Industrial and Applied Mathematics.

[50] Hindmarsh, A.C., Petzold, L.R., 1995. Algorithms and software for ordinary differential equations and differential-algebraic equations, Part II: Higher-order methods and software packages Computers in Physics 9(2), 148-155.

[51] Curtis, A.R., Powell, M.J.D., Reid, J.K., 1974. On the Estimation of Sparse Jacobian Matrices. Journal of the Institute of Mathematical Applications 13, 117-119.

[52] Hindmarsh, A.C., 1982. Large ordinary differential equation systems and software. IEEE Control System Magazine 2, 24-30. 
[53] Vauclin, M., Khanji, D., Vachaud, G., 1979. Experimental and numerical study of a transient, two-dimensional unsaturated-saturated water table recharge problem. Water Resources Research 15, 1089-1101.

[54] Forsyth, P.A., Kropinski, M.C., 1997. Monotonicity considerations for saturatedunsaturated subsurface flow. SIAM Journal on Scientific Computing 18, 1328-1354.

[55] Huang, K., Mohanty, B.P., van Genuchten, M.T., 1996. A new convergence criterion for the modified Picard iteration method to solve the variably saturated flow equation. Journal of Hydrology 178(1-4), 69-91.

[56] United Nations Development Program. Assessment of Groundwater Resources of Lebanon. Ministry of Energy and Water, Beirut, Lebanon.2014.

[57] Van Vuuren, D., Edmonds, J., Kainuma, M., Riahi, K., Thomson, A., Hibbard, K., 2011. The representative concentration pathways: an overview. Climatic Change 109, 531.

[58] FAO., 1970. Projet de Développement Hydro-Agricole: Etude Hydrogeologique De La Plaine D'Akkar. République Libanaise, Ministère des Ressources Hydrauliques et Électriques, Beyrouth, Liban. 